\title{
Rare Location and Clinical Presentation of Gout Disease: Distal Ulna Localized Gout Disease and Acute Gout Attack of the Wrist
}

\author{
Recep Ozturk (D), Huseyin Dogan (D), Emek Mert Duman (D), Bedii Safak Gungor (D) \\ Dr. Abdurrahman Yurtslan Ankara Oncology Training and Research Hospital, Department of Orthopaedics and Traumatology, Ankara, Turkey
}

Correspondence Author: Recep Ozturk

E-mail: ozturk_recep@windowslive.com

Received: $03.03 .2019 \quad$ Accepted: 28. 02.2020

\begin{abstract}
Gout is one of the most common inflammatory arthritis in adults. This disorder is caused by the accumulation of monosodium urate crystals in soft tissues and joints because of the hyperuricemia. One of the lower extremity joint especially the first metatarsophalangeal joint is affected by more than $75 \%$ of the gout attacks. In this study, we reported a rare presentation of gout disease, the acute gout attack of the wrist, in a woman, 72 years aged, who has not been diagnosed before. Gout which occurs with the involvement of the wrist is very rare and no other cases with distal ulna localization have been reported according to our knowledge. We reported the first case of gout disease which started from distal ulna. The patient was operated because the symptoms did not recover with conservative treatments.
\end{abstract}

Keywords: Gout, wris, acute attack, ulna, tophi.

\section{INTRODUCTION}

Gout disease is the most common inflammatory arthritis in the elderly (1). One of the lower extremity joint especially the first metatarsophalangeal joint is affected by more than $75 \%$ of the gout attacks that is known as podogra (2). Acute gout arthritis of the wrist is a rare case and we could not find any other gout lesion which is localized in the distal ulna by our recent literature search. The incidence of the gout disease is increasing by aging and is more common in men (3). The prevalence of self-reported physician-diagnosed gout is more than $2 \%$ in men older than 30 years and in women older than 50 years. The hand and the wrist involvement is more common in women (4).

We aimed to present a rare arthritis case which is the first example of the wrist localized gout in the distal ulna.

\section{CASE REPORT}

Seventy-two years aged a woman, who complaining swelling and pain on the right wrist applied to our department. Her complaints were present for about last 15 days and their severity was increasing recently. The redness, tenderness and swelling on the right wrist is very remarkable and this situation restricted the range of motion of the wrist. C-reactive protein was high $(41.0 \mathrm{mg} / \mathrm{dl})$ and serum uric acid level was normal $(4.7 \mathrm{mg} / \mathrm{dl}$, normal range is between 2.4 and $7 \mathrm{mg} / \mathrm{dl}$ for men) found by laboratory results.

She had swellings on her all fingers and wrist, had extreme sensitivity to palpation and marked motion loss. When we look at her detailed history, she applied to another hospital complaining of pain in her left wrist about 3 years ago. She was told there was a mass lesion on her left wrist around distal ulna and she should be followed up for her lesion. Although the patient suffered from pain time to time she never applied to the hospital for following up again.

There was an expansile lytic view with irregular borders accompanied by peripheral periost reaction around the epiphyseal-metaphyseal region of distal ulna on direct graphy. Besides, a volume increase related to soft tissue edema or effusion was observed most prominent around the volar side (Figure 1). Also, there was a view that is heterogenously hyperintense on $\mathrm{t} 2$ weighted image and that is isointense with muscle on $t 1$ weighted image around distal ulna on MRI. There has been minimal effusion on distal radioulnar and proximal carpal joints. Effusion related to tenosynovitis around carpal tunnel and extensor carpi ulnaris tendon. A degenerative cystic lesion was observed in lunate bone (Figure 2). 


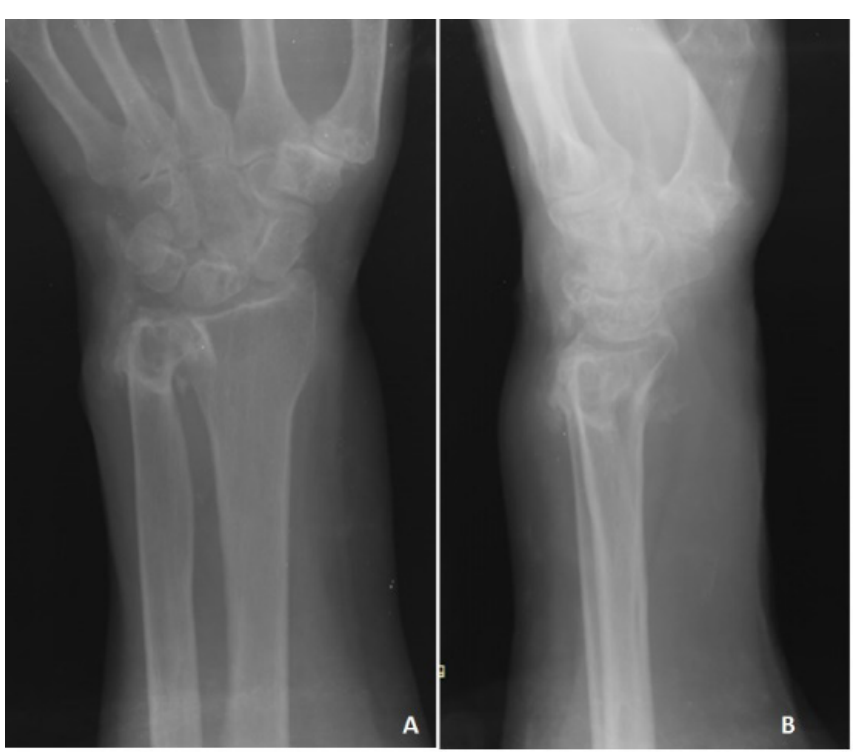

Figure 1. There is an expansile lytic view with irregular borders accompanied by peripheral periost reaction around the epiphysealmetaphyseal region of distal ulna on direct graphy.

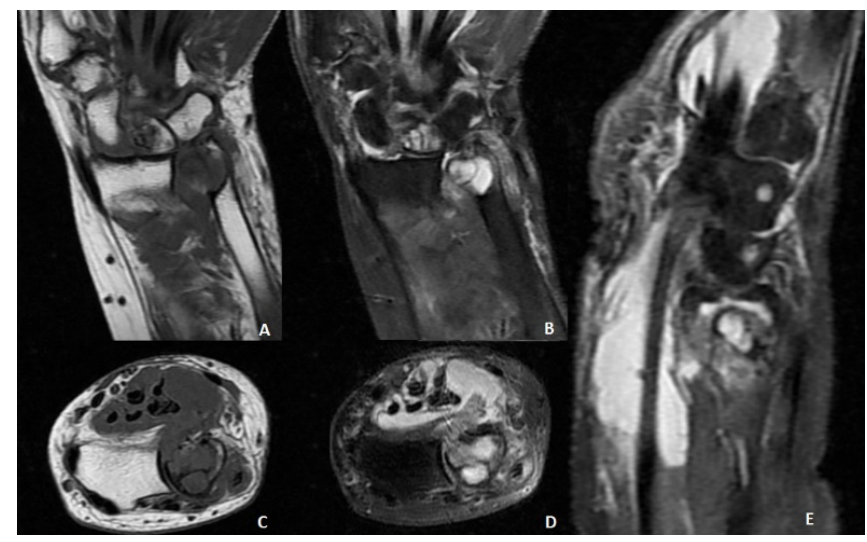

Figure 2. There is a view that is heterogenously hyperintense on $t 2$ weighted image and that is isointense with muscle on 11 weighted image around distal ulna on MRI. There has been minimal effusion on distal radioulnar and proximal carpal joints. Effusion related to tenosynovitis around carpal tunnel and extensor carpi ulnaris tendon. A degenerative cystic lesion was observed in lunate bone.

The acute gout attack was thought by considering the diagnosis criteria of American College of Rheumatology and clinical, radiological and the history of the patient evaluation results (5).

Resolution of the attack was seen in five days after the start of $25 \mathrm{mg}$ diclofenac sodium three times a day. The operation was planned because of persistent pain, swelling, loss of motion and suspicious diagnosis. The macroscopic appearance of the lesion gave rise to thought gout in intraoperative evaluation. Fresh frozen examination was reported as it is coherent with gout. The lesion was debrided and carpal tunnel release were performed. The area of involvement in the distal ulna was completely curetted and debrided. Static wrist splint was worn for 20 days. The patient was consulted to rheumatology department for medical treatment.

\section{DISCUSSION}

Gout is an inflammatory arthritis caused by the accumulation of monosodium urate(MSU) crystals in synovial fluid and it is associated with hyperuricemia. It was described for the first time by Egyptians in B.C. 2640 (3).

The incidence increases by aging and gout is more common among men. The definitive diagnosis of gout disease is best established by demonstration of monosodium urate crystals in the synovial fluid or biopsy $(3,6)$.

Tophaceous gout occurs years after recurrent attacks of acute inflammatory arthritis (7). Hand and wrist tophaceous gout, often seen as the first symptom of the disease process in the elderly (4). Synovitis and bone lesions on direct radiography and MRI are common lesions of the wrist even in the first episode of acute gout arthritis (8). Tophaceous involvement of the wrist may be limited to either the flexor or extensor compartment, or it may be permeative and include the wrist joint itself. Tendon infiltration, tendon rupture and rarely skin ulcers may develop in neglected aggressive cases (4). The involvement of radiocarpal, intercarpal and distal radioulnar joints is rare. Uncontrolled or untreated gout in these joints may lead to scapho-lunate dislocation and severe joint damage $(2,4,8)$. The involvement of the flexor surface of the wrist may lead to carpal tunnel syndrome which is often seen in chronic cases $(9,10)$.

In addition, Bouaziz et al. reported a case of infected gout tophus located at the wrist and Skedros et al. reported compartment syndrome in the wrist in $2018(7,11)$. Kamimura et al. reported a case of acute gout attack on the wrist in 2004 (2). Jacob et al. reported a rare and unusual gout attack on the wrist, induced by a change in the dosage of anti-hypertensive drug in 2007 (1).

Radiographies and magnetic resonance imaging are usually helpful to understand the changes in the bone and soft tissue related to gout and tophus. Also they are helpful to differentiate gout and tophus from the other joint diseases and tumoral lesions (12).

The patients with typical podagra can be diagnosed as gout on clinical examination. Joint aspiration is recommended for the patients who has atypical joint involvement to demonstrate monosodium urate crystals and exclude other causes of acute arthritis (13).

Diseases such as rheumatoid arthritis, osteoarthritis, septic arthritis, calcium pyrophosphate dihydrate crystal deposition disease, psoriatic arthritis and tumoral lesions should be considered in the differential diagnosis of gout $(1,14)$.

Gout disease has no a specific treatment. Antihyperuricemic therapies may provide benefit, and low dose steroids may control the pain and inflammation. Surgical treatment is indicated in cases refractory to medical therapy and 
suspicious diagnosis. Surgical treatment may be simple as squeezing the pasty tophaceous material and fluid aspiration but sometimes surgical decompression may be needed. Following surgical decompression, pharmacological treatment and lifestyle modifications are of paramount importance (15-18).

\section{CONCLUSION}

It should be kept in mind that inflammatory signs on the wrist of elderly patients may be related to the first presentation of gout and that radiographical and MRI changes may be present even in the first presentation. Surgical treatment may be used in cases that does not benefit from medical treatment or are difficult to diagnose. In addition, a multidisciplinary approach is principle in the treatment of gout.

\section{REFERENCES}

[1] Jacobs CL, Stern PJ. An unusual case of gout in the wrist: the importance of monitoring medication dosage and interaction. A case report. Chiropr Osteopat. 2007;15(1):1-5.

[2] Kamimura T, Hatakeyama M, Okazaki H, Minota S. Acute gout attack in the wrist joint. Intern Med. 2004;43(7):641-642.

[3] Gaviria JL, Ortega VG, Gaona J, Motta A, Medina Barragán OJ. Unusual dermatological manifestations of gout: review of literature and a case report. Plast Reconstr Surg Glob Open 2015;3(7):1-6.

[4] Fitzgerald BT, Setty A, Mudgal CS. Gout affecting the hand and wrist. J Am Acad Orthop Surg. 2007;15(10):625-635.

[5] Wallace SL, Robinson H, Masi AT, Decker JL, McCarty DJ, Yu TF. Preliminary criteria for the classification of the acute arthritis of primary gout. Arthritis Rheum 1977;20(3): 895-900.

[6] Purohit MB, Purohit TM, Tandon RK. FNAC of gouty tophi-a case report. Indian J Pathol Microbiol 2006;49(1):42-43.
[7] Bouaziz W, Rekik MA, Guidara AR, Keskes H. Infection of a tophaceous nodule of the wirst and hand. BMJ Case Rep 2018;28(1):81-84.

[8] Cimmino MA, Zampogna G, Parodi M, Andracco R, Barbieri F, Paparo F, Ferrero G, Garlaschi G. MRI synovitis and bone lesions are common in acute gouty arthritis of the wrist even during the first attack. Ann Rheum Dis. 2011;70(12):22382239.

[9] Kalia KK, Moossy JJ. Carpal tunnel release complicated by acute gout. Neurosurgery. 1993;33(6):1102-1103.

[10] Lu H, Chen Q, Shen H. A repeated carpal tunnel syndrome due to tophaceous gout in flexor tendon: A case report. Medicine (Baltimore). 2017;96(9):1-4.

[11] Skedros JG, Smith JS, Henrie MK, Finlinson ED, Trachtenberg JD. Upper extremity compartment syndrome in a patient with acute gout attack but without trauma or other typical causes. Case Rep Orthop. 2018;23(1):1-6.

[12] Bousson V, Hamze B, Wybıer M, Daguet E, Parlier C, Petrover D, Bossard P, Laredo JD. Soft tissue tumors and pseudotumors of the foot and ankle. j radiol 2008; 89(1): 21-34. [Article in French]

[13] Abhishek A, Roddy E, Doherty M. Gout - a guide for the general and acute physicians. Clin Med (Lond). 2017;17(1):54-59.

[14] Atalay iB, Yapar A, Öztürk R, Ulucaköy C, Toptaş E. Surgical outcomes of synovial osteochondromatosis: an evaluation of 15 cases. Acta Oncol Tur. 2019; 52(3): 379-382

[15] Ochoa CD, Valderrama V, Mejia J, Rondon F, Villaroya N, Restrepo JF, Espinoza LR, Iglesias-Gamarra A. Panniculitis: another clinical expression of gout. Rheumatol Int. 2011;31(6):831-835.

[16] Öztürk R, Atalay ỉ, Bulut EK, Beltir G, Yılmaz S, Güngör BŞ. Place of orthopedic surgery in gout. Eur J Rheumatol. 2019;6(4):212-215.

[17] Weberschock T, Gholam P, Hartschuh W, Hartmann M. Gouty panniculitis in a 68-year-old man: case report and review of the literature. Int J Dermatol 2010;49(4):410-413.

[18] Martin D, Joliat GR, Fournier P, Brunel C, Demartines N, Gié O. An unusual location of gouty panniculitis: a case report. Medicine (Baltimore). 2017;96(16):1-3. 